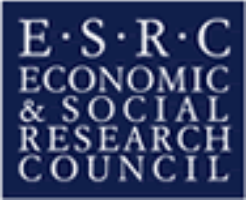

\title{
The Livestock Mandatory Reporting Act: Has Information Pooling Led to Anticompetitive Behaviour in the US Beef Industry?
}

by

\author{
Andrew D. Bugg \\ School of Economics \& ESRC Centre for Competition Policy, \\ University of East Anglia, UK \\ CCP Working Paper 05-6
}

\begin{abstract}
Cointegration analysis has been used to assist the testing for price delineation in antitrust and merger cases as a way of deepening econometric evidence. This paper examines the impact of the Livestock Mandatory Reporting Act (1999) instigated in 2001. By addressing the industry as a cointegrated system containing retail, wholesale and farm prices, short run and long run relationships were examined. Cointegration analysis between farm, wholesale and retail sectors suggests that the wholesale sector plays an important role within system. The econometric estimations find that long run wholesale pricing is weakly exogenous whilst farm and retail prices follow the same trend. This finding suggests that it may be as a result of market inefficiency and calls for further analysis of the role that the wholesale sector plays within the industry.
\end{abstract}

May 2005

JEL classification: D8; D34; L11; L66; Q13

Keywords: Information pooling; Mandatory price reporting; Livestock markets; Cointegration; Empirical industrial organisation.

Acknowledgements:

The author would like to thank Peter Moffatt and Bruce Lyons for extensive comments and Heather Savigny for additional comments. Support from the Economic and Social Research Council is gratefully acknowledged.

Contact Details:

School of Economics, University of East Anglia, Norwich, NR4 7TJ, UK.

Email: a.bugg@uea.ac.uk. 


\section{The Livestock Mandatory Reporting Act: Has Information Pooling Led to Anticompetitive Behaviour in the US Beef Industry?}

\section{Introduction}

Did the introduction of information pooling mandated by the Livestock Mandatory Reporting Act of 1999 lead to anticompetitive behaviour in the US beef industry? In January 2001 the Livestock Mandatory Reporting Act was introduced to gather information in order to promote competition in the marketing of livestock and livestock products. However, in this paper it is argued that the introduction of information pooling did, in fact, result in anticompetitive behaviour. Other work that has investigated cases of government assisted information pooling has shown that it can potentially lead to anticompetitive behaviour (see Albæk et al., 1997). Therefore, this paper presents an empirical analysis testing for the presence of any sectoral (retail, wholesale or farm) anticompetitive behaviour in light of recent price transparency policy ${ }^{1}$. A Johansen and Juselius (1990) cointegration test is applied to monthly time series data between the period of January 1998 and February 2003 to test for any price delineation of any sectoral price regimes away from the industry long run equilibrium. Any detected movement away from the industry long run equilibrium may be a result of anticipated anticompetitive behaviour.

The chosen time period is set to reflect a 'before' and 'after' analysis of the introduction of price transparency. Furthermore, it was chosen to reflect and perhaps exaggerate the possibility of a 'structural break' in the set of beef prices, indicating a potential change in the pricing strategy within the retail sector at the point of introduction of price transparency.

The purpose of this paper is to add to the literature an analysis of the short run and long run dynamics of the industry as a system containing farm, wholesale and retail sector pricing mechanisms. Azzam and Salvador (2004) is the only other known work that has looked at the introduction of information pooling as a result of The Livestock Mandatory Reporting Act. They test for collusion across five regions of the US and suggest evidence of non-collusive behaviour in the State of Nebraska but inconclusive evidence in other States.

Cointegration analysis has been used to assist cases of antitrust and mergers because it holds several key advantages over simpler econometric studies being used as evidence in this field. First, it allows different variables such as the price for a good and its substitutes within a geographical market to be modelled as within one market to see if they belong to that market. Second, it tests for the long run relationships between prices that are possibly hidden by noise created by the short run fluctuations within the data. Third, it provides a statistically

\footnotetext{
${ }^{1}$ Farm, wholesale and retail sectors make up the vertical stages of the US beef industry. The wholesale stage constitutes slaughter and meat packing. It is at these three stages that information on price is collected by the Economics Research Service.
} 
viable method of testing for the possibility of price delineation. It is this advantage that we hope will shed light on whether or not information pooling has led to anticompetitive behaviour. Fourth, it can be used to test the viability of simpler regression analysis presented in antitrust and merger cases. Fifth, it has been tried and tested by the European Commission.

The outcome of this paper is interesting for policy in this area. Retail, wholesale and farm prices are found to be cointegrated and thus there is a unique combination of the three time series that is stationary. Furthermore, the cointegration analysis highlights that the wholesale sector is a vital element of the system and in the long run was found to be weakly exogenous to the system and therefore is driven by a separate stochastic trend. The implications of this finding, point to the probability that, the introduction of information pooling has not led to increased market efficiency, as a result of information being available to a wider audience. Instead, there is evidence to suggest that there was market inefficiency which may have been due to some form of anticompetitive behaviour being exercised by the wholesale sector. One possible reason for this finding could be the increase in vertical coordination between producers and wholesalers. Furthermore, there is no evidence of anticompetitive behaviour within the retail sector as a result of price transparency through retail scanner data being widely available on the internet.

The next section introduces the background to this paper. The aim of the next section is to introduce the Livestock Mandatory Reporting Act of 1999 and also present some current themes within the literature surrounding the US beef industry. The paper then goes on to introduce some descriptive analyses of the data that was used in the empirical testing. Furthermore, section four introduces the empirical model to be tested followed by the results of the estimations given in section five. The paper then concludes with a summary of the papers findings and their implications.

\section{Background}

The Mandatory Reporting Act (the Act hereafter) was introduced in 1999, in reaction to concerns of increasing levels of industry concentration, and its resulting negative implications on the bargaining power of agricultural producers at one end of the industry and consumers at the other. Furthermore, other problems within the industry such as poor farming returns, high farm input prices, increasing gaps between farm and retail prices, and a falling share of retail prices reaching the producer have also contributed to the need for government intervention (Mathews et al., 1999). The Act itself has the following objective: “ "... to establish a program of information regarding the marketing of cattle, swine, lambs, and products of such livestock...”" (Livestock Mandatory Reporting Act, pg. 1). For the purposes of this paper we

\footnotetext{
${ }^{2}$ http://www.ers.usda.gov/Data/Meatscanner/LivestockMandatoryReportingAct.pdf
} 
focus our attention upon its impact on the US beef industry. This is because of two central reasons. First, it was necessary to select one sector of the US agricultural industry mandated by the Act where data was readily available for analysis. Second, the US beef industry had been experiencing an interesting period of transition that made it a particularly interesting case study.

The Mandatory Reporting Act (1999) has three main functions in its power: “ “.. (1) provides information that can be readily understood by producers, packers, and other market participants, including information with respect to the pricing, contracting for purchase, and supply and demand conditions for livestock, livestock production, and livestock products; (2) improves the price and supply reporting services of the Department of Agriculture; and (3) encourages competition in the marketplace for livestock and livestock products." (Livestock Mandatory Reporting Act, 1999). The opportunity to assess the introduction of the Act since its formal inauguration in 2001 is inviting. Therefore, the question that we seek to answer through the forthcoming methodology is: Have farmers, wholesalers or retailers been affected as a result of more information being available within the industry? For example, are their price regimes affecting the industry long run equilibrium in an anticompetitive way?

The concentration of the beef sector was a major factor in the decision to implement the Act. For example, Harris (2002) noted its high concentration with a high four-firm concentration ratio for steer and heifer slaughter which rose from $70 \%$ in 1989 to $81 \%$ in 1999. The production sector in the US has been subjected to much structural change in the last thirty years caused by falling population levels and export growth. The major elements of structural change were induced by horizontal concentration and vertical integration between meatpackers and producers. Vertical integration has led to the expansion of large 'feedlots' where steers and heifers are produced at a very intensive scale (see MacDonald et. al., 1999). Coordination of this magnitude reduces inefficiencies and creates positive externalities for such mergers by way of economies of scale, reduction of distribution overheads as a result of internalised costs and the ability to maintain a continuous throughput of animals for slaughter. The effect upon non-merged producers is an interesting area of research, as noted by Sexton and Xia (2003). This area is of interest because it provides motivation and the necessary reasoning for the Act as a form of protection against the growing isolation of farmers, as noted by Haley (2001): "Many small independent livestock producers, who continue to market small numbers of animals through spot markets point to the restructured industry as justification for MPR [Mandatory Price Reporting].” (pg. 5)

Sexton and Xia (2003) provide a discussion of the contractual relationships between wholesalers and producers. They model the competitive implications of Top-of-the-Market Pricing (TOMP) clauses on producers and argue that such contracts with the ability for meatpackers to commit to a future purchase at a: 'spot price to be determined later' (pg. 2) 
can lead to anticompetitive actions resulting in a negative impact upon those producers involved. This is further evidence for the need for asymmetry of information within the industry.

The retail sector in the US has also been subjected to massive change. Along with changes in marketing styles and products on offer, retailers have been subjected to high levels of mergers and acquisitions. Kaufman (2002) noted that the largest four food retailers accounted for $27.4 \%$ of the total US retail sales in the year 2000. The increasing levels of concentration may lead to increased buying power from down stream elements. Wholesalers may be subjected to tougher pricing agreements by retailers. In terms of the beef industry, this is a worrying aspect for wholesalers and indeed producers. Kaufman (2002) also suggested that: “... consolidation among large retailers will likely contribute to increased direct procurement of products from food and agricultural suppliers." (pg. 33) The implication of increasing consolidation in the retail and wholesale sectors is indeed the major reason for the need to introduce price transparency powered by the Act.

The establishment of price transparency within the retail market for beef may have similar implications to that of anticompetitive contracts in up stream markets. It is likely that, with greater knowledge of rivals' prices and, therefore, each others discounts, retailers are more likely to converge in pricing or collude to set a higher price. This study aims to assess if sectored exogenous pricing is present that, may highlight the presence of some form of market power in the industry. Of course, it is highly likely that the opposite could be the case, where, price transparency only opens the door to a greater level of discounting by retailers, to enhance competition within the sector, leading to lower prices and, ultimately, a welfare improvement for consumers.

This argument is particularly specific with regard to the countervailing power argument within US retail beef market. Countervailing power as defined by von UngernSternberg (1996) is: “... the potential of market power by large firms is often curbed not by competition from other firms at the same horizontal level, but by powerful firms on the demand side that manage to extract competitive prices ..." (pg. 507). This is a critical issue that could be utilised by retailers to extract high prices especially in a period of symmetric information in the market. This is not only an issue for consumers but also for producers that rely on 'spot' prices as opportunities to sell their produce. As Sexton and Xia (2003) suggested the ability of wholesalers and ultimately meatpackers to enter into contractual agreements on the price for future production invites the opportunity to weaken the competitive nature of the producer. For a rational producer such contracts may be plausible but collectively they are damaging (pg. 31). Arguably, any form of contract that offers future markets, and best-price clauses, are capable of assisting collusion. Therefore, the producers, 
as a group, will ascertain a lower than the expected price as a result of meatpacker buying power.

The current issues in the US beef market revolve centrally around increasing concentration levels. First, within the retail sector the Act has been introduced to prevent the possibility of countervailing power upon wholesalers of meat in general and, ultimately, to make the retail meat market more competitive. Second, it is apparent that concentration in the meatpacking sector of the industry is a potential problem for producers. The ability of wholesalers, through mergers and acquisitions, to reduce the selling power of producers, is a concerning factor for the ability of a lone producer gaining a fair price. Indeed, countervailing power may be a factor in the ever consolidating meatpacking sector. This summary of the current issues in the US beef industry provides the background to the reasons why the Act was introduced. The following section introduces the data used in the empirical analysis.

\section{Data and Descriptive Analysis}

Table 1 opposite shows some descriptive statistics for all three of the price series used in the estimation. The standard deviation, a measure of the spread of a distribution, indicates that for all of the variables there are only small deviations from the mean. By breaking the data for each sector up into 'before' and 'after' cases it is possible to see that the wholesale sector has on average been decreasing the variability of its price setting behaviour given a smaller standard deviation after the Act was implemented. In comparison, retail prices on average have become more variable after the Act was put into force. So too have farm prices, but to a much lesser extent. This suggests that as a result of the Act and the introduction of price transparency the retail sector are pricing competitively.

Applying a Jarque-Bera ${ }^{3}$ test for normality, suggested that all variables follow a normal distribution which show a significant level of significance at chi-square with two degrees of freedom. This indicates that the distributions of these variables are asymptotic. Table 1 also presents the summary statistics for the commercial beef slaughter for 'all beef', sourced form the National Agricultural Statistics Service. Increasing average commercial slaughter after the implementation of the Act indicates that the Act has been successful in achieving one of its aims in the early months of its existence.

In order to build a data set that would represent a price series between January 1998 and February 2003, proxy price data ('all beef' retail value) was used to represent retail 'all beef' prices in the period between January 1998 and December $2000^{4}$. This data was sourced

\footnotetext{
${ }^{3}$ For further explanation of the results, please see appendix A.

${ }^{4}$ For scanner data: www.ers.usda.gov/data/meatscanner and then choose appropriate link and for meat price spreads: www.ers.usda.gov/briefing/foodspreads/meatpricespreads.
} 
from the ERS meat price spread dataset. The Economic Research Service (ERS) records this data by calculating the value of a standard animal and assesses its value at the three different stages of the market for beef. Thus, the ERS considers the farm, wholesale and retail value of the animal enabling the value of the animal, at each stage of the market to be compared. The methodology behind its calculation refers to 'all beef', therefore, fitting the category of 'all beef' also found in scanner retail price databases. To complete the series, retail 'all beef' scanner price data was added to the series from January 2001 up to February 2003.

\begin{tabular}{ccccc}
\hline & Observations & Mean & Median & St. Deviation \\
\hline Retail Beef Price (BP) & 62 & 278.12 & 278.81 & 20.99 \\
Before Act & 36 & 263.00 & 259.00 & 10.35 \\
After Act & 26 & 299.00 & 256.00 & 13.06 \\
\hline Wholesale Price (WP) & 62 & 177.00 & 177.81 & 15.97 \\
Before Act & 36 & 170.00 & 171.00 & 15.33 \\
After Act & 26 & 187.00 & 186.00 & 10.83 \\
\hline Farm Price (FP) & 62 & 161.71 & 158.60 & 11.91 \\
Before Act & 36 & 157.30 & 155.95 & 10.31 \\
After Act & 26 & 167.80 & 167.95 & 11.46 \\
\hline Commercial Slaughter (Millions/lbs) & 62 & 2197.56 & 2199.00 & 137.3578 \\
Afore Act & 36 & 2189.33 & & \\
\hline
\end{tabular}

Table 1 Descriptive Statistics; Retail, Wholesale, Farm prices (Cents/lb) and Commercial Slaughter (Millions/lb)

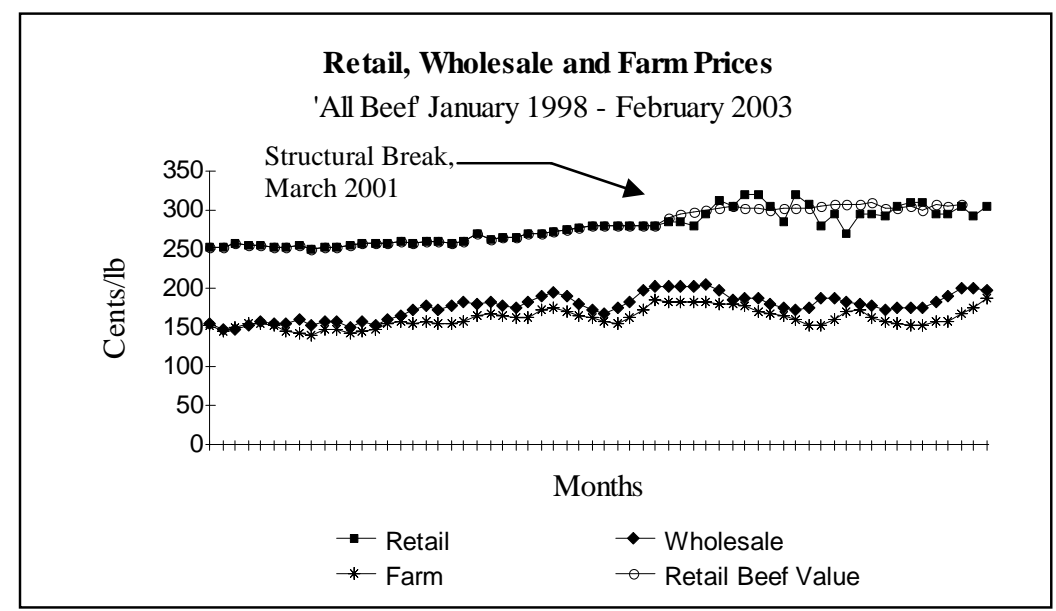

Figure 1 Retail, Wholesale and Farm 'All Beef' Prices, Cents/lb; Monthly between January 1998 and February 2003

Figure 1 above shows a discontinuous trend from 2001 to 2003 for retail beef prices. This element of discontinuity does provide for weaknesses in the use of the constructed price series. Figure 1 also demonstrates that if the retail scanner prices were not added to the retail 'all beef' value from 2001, the series would continue on a constant upward trend. The introduction of scanner prices from 2001 has resulted in the price fluctuating around the value 
price level with some evidence of convergence in late 2002. The use of a standard Chow test identified that a structural break was present for March $2001^{5}$. Therefore, there is evidence to suggest that the inclusion of scanner prices into the series to represent 'all beef' retail prices has caused a structural break.

The wholesale price series data was obtained from the United States Department of Agriculture (USDA) meat price spread database ${ }^{6}$. It represents the value of 'all beef' at the wholesale stage of the market as a proxy for wholesale prices ${ }^{7}$. The wholesale series, also displayed in Figure 1, provides a continuous and upward trend of between 150 and 200 cents per pound over the time period, with a peak of 203 Cents in month 36 (the end of year 2000). Unlike the retail scanner price data, which included a proxy of 'all beef' value up to 2001 possibly inducing a structural break, the wholesale value is from a continuous source. Thus, there is a possibility that the decreasing trend after 2001, which coincides with the introduction of the Act, could be linked to price transparency of retail prices. If for example, retailers were to exert market power (possible collusion on pricing), then the wholesale sector may be forced with countervailing power to supply retailers at a lower price, otherwise leading to the possibility of being outsourced by other wholesalers.

Figure 1 also suggests a cyclical nature for the value placed upon 'all beef' at the wholesale stage of the beef industry. Seasonality is a factor in the beef industry but severe cyclical alterations are less likely to be present within the prescribed time frame of 62 months and are more likely to be present over longer time periods due to the nature of the farming systems in place to produce cattle for slaughter. As with the wholesale 'all beef' price, the farm beef value is also described by a proxy variable. The value of 'all beef' at the farm level is used to proxy the farm price for 'all beef' as sourced from the ERS ${ }^{8}$ Figure one provides a graphical representation of the proxy series.

The series is continuous in the bounds between 150 cents per pound and 200 cents per pound. The farm value does have a cyclical nature but this is most obvious in the years 2000 and 2001 where the value peaks at 183 Cents per pound at the beginning of the year 2001 . The series then falls to a value of 152 cents per pound at the beginning of 2002 rising to 172 cents per pound in mid 2002 before increasing to 187 cents per pound in February 2003. The upward trend shown between 1998 and 2001 appears to weaken, although modestly, between 2001 and 2003. This may be due to similar influences as placed upon the stabilising prices of the wholesale sector, such as the falling bargaining power of farmers.

\footnotetext{
${ }^{5}$ In order to test for a structural break around the introduction of scanner price data, a Chow test was conducted. The standard Chow test, as described by Gujarati (2003), tests for "differences or structural changes caused by differences in the intercept or the slope coefficient or both" (pg. 275). The test result, given by an F-statistic, provided strong significant evidence that a structural break is present for the month of March 2001.

${ }^{6}$ Source: ERS/USDA, www.ers.udsa.gov/briefing/foodpricespreads/meatpricespreads/ and follow the appropriate links.

${ }^{7}$ The definition given by the ERS for the wholesale value is the value of the animal with regard to its varying cuts at the wholesale stage of processing. For example, beef is processed up to a level where it can be supplied to the retail stage for additional processing to cuts and joints suitable for the retail market for beef.

${ }^{8}$ Source: ERS/USDA found at: www.ers.udsa.gov/briefing/foodpricespreads/meatpricespreads/
} 
The descriptive analysis has presented three main findings. First, increasing average commercial slaughter after the Act was introduced indicates that the Act has been successful. Second, there appears to be evidence for a structural break in the retail price series around the time of the implementation of the Act. Furthermore, the standard deviation of retail prices after the Act was introduced suggests that prices are more variable. These two findings may point towards the retail sector becoming more competitive as a result of price transparency. Third, the standard deviation of wholesale prices decreases after the Act was introduced which may suggest that the wholesale sector is pricing inefficiently. These findings point towards the need for a more complex examination of pricing behaviour.

\section{Empirical Model}

The following methodology attempts to examine the short and long run relationship between farm, wholesale and retail prices in the US beef industry. The models use retail, wholesale and farm prices across the same period for the ERS 'all beef' category. The discovery of prices moving away from the industry equilibrium (exogenous pricing), within any of the three sectors could be evidence to suggest a presence of anticompetitive pricing strategies.

Testing for cointegration between retail, wholesale and farm beef prices in the US beef market with Vector Autoregressive models (VAR) and Error Correction Models (ECM) provides estimates of long run and short run dynamics necessary to assess the velocity of price adjustments. The next section goes onto explain the estimation process. First, tests for structural form are used to establish that each series are appropriately stationary. Second, the VAR is presented and, finally, the test for cointegration is explained.

\subsection{Preliminary Tests for Structural Form}

Each price series was subjected to Augmented Dickey-Fuller tests for unit roots to establish that all series are stationary. This is a necessary requirement for the correct application of the ECM. Second, the series were subjected to a Likelihood Ratio (LR) test to establish the significant lag length. This involved computing the forthcoming VAR at varying lag levels and computing the LR test. The LR test resulted in three lags being highly significant, therefore lag length, $p$, was set to three. The tests are presented in appendix B to conserve space. All series are stationary at first difference with high levels of significance.

\subsection{The Vector Autoregression Model}

Engle and Granger (1987) showed that the construction of a VAR model in first differences by the Granger Representation theorem with error correction capabilities is the same as an ECM using a set of variables that are integrated of order one, implying cointegration between 
the variables. This format was used by Chang and Griffith (1998) for an examination of long run relationships between Australian beef prices. In the case of the US beef prices the following model was used to examine the relationship between prices. The model structure involves taking a standard $\operatorname{VAR}$ with a lag length $p, \operatorname{VAR}(p)$ :

$x_{t}=A_{0}+A_{1} x_{t-1}+\ldots+A_{p} x_{t-p}+\gamma D B P_{t}+u_{t}$

Where: $p$ is the lag length; $x_{t}=\left(B P_{t}, W P_{t}, F P_{t}\right)^{\prime}$ is a vector of retail, wholesale and farm prices; $A$ 's and $B$ are unknown parameters; $x_{t-i}=\left(B P_{t-i}, W P_{t-i}, F P_{t-i}\right)^{\prime}$ for $i=1,2,3, \ldots p$; $D B P_{t}$ is a dummy variable for $B P_{t}$ after the introduction of price transparency to control for any structural changes; and $u_{t}$ is the error term.

\subsection{The Johansen \& Jeselius Test for Cointegration}

In order to test for cointegration it is necessary to formulate the ECM. The ECM is simply the VAR in first differences with error correction terms added. A Johansen \& Jeselius test was then applied to the vector of prices $x_{t}$ to examine whether any cointegrating relations existed. The existence of any relations implies that stationary long run trends are present, providing for the correct specification of the ECM. The ECM, given the Granger Representation theorem contains a set variables that are integrated of order one which implies cointegration between the three price variables. The Johansen and Jeselius procedure takes the following form:

$$
\begin{aligned}
& \Delta x_{t}=\Pi_{0}+\Pi_{i} \Delta x_{t-1}+\ldots+\Pi_{p-1} \Delta x_{t-(p-1)}+\Pi x_{t-p}+\gamma B D_{t}+u_{t} \\
& \Delta x_{t}=\Pi_{0}+\sum_{i=1}^{p-1} \Pi_{i} \Delta x_{t-i}+\Pi x_{t-p}+\gamma B D_{t}+u_{t}
\end{aligned}
$$

Where: $\Delta x_{t}=\left(\Delta B P_{t}, \Delta W P_{t}, \Delta F P_{t}\right)^{\prime}$ is a vector of retail, wholesale and farm prices in first differences; $\Delta x_{t-i}=\left(B P_{t-i}, W P_{t-i}, F P_{t-i}\right)^{\prime}, \quad i=1,2, \ldots, p-1 ; \Pi_{i}{ }^{\prime} s$ are a $(3 \times 3)$ matrix of unknown parameters representing the short run dynamics; $\Pi=\alpha \beta^{\prime}$ is the matrix of unknown parameters representing the long run dynamics; $B D_{t}$ is a dummy variable for $B P_{t}$ after the introduction of price transparency to control for any structural changes; and $u_{t}$ is the error term. 
As shown by Greene (2003), in this case $\Pi$ produces all the linear combinations of the variable $x_{t-p}$. The matrix $\Pi$ produces the long run impact matrix of the ECM and the matrix $\Pi_{i}$ gives the short run dynamics of the model. It is these two matrices that will provide information on the dynamics of the industry.

The matrix $\Pi$ is of the following form: $\Pi=\alpha \beta^{\prime}$, where $\alpha$ estimates the velocity of adjustment coefficients and $\beta$ is the matrix of cointegrating relationships in the vector $x_{t}$. The size of $\alpha$ reflects the speed at which the system of equations responds to shocks away from the long run equilibrium. A small $\alpha$ refers to a small response and vice versa. The statistical significance of the adjustment coefficients provides an indication of the pricing strategies within the industry. For example, exogenous prices in the long run would point towards suspicion regarding the behaviour of that sector. Furthermore, it may highlight the presence of some anticompetitive behaviour as a result of market inefficiencies.

This model is useful as cointegration between a set of variables implies a long run stationary trend for prices at all levels of the industry. The ECM framework also deals with the problem of non-stationary variables. The nature of the response made by the model to deviations away from the long run trend is an indication of the link between the series within the system of equations in the ECM approach. The next section presents the hypotheses to be tested.

\subsection{Hypotheses}

To recapitulate the overarching aim of this paper, we are fundamentally interested in detecting if the introduction of price transparency has impacted upon the pricing behaviour of each sector. For short run relationships between retail, wholesale and farm prices the following hypothesis is to be tested:

$H_{0}^{S R}: \Pi_{i}=0$

and $H_{1}^{S R}: \Pi_{i} \neq 0$

Where $\Pi_{i}$ is a matrix representing the short run dynamics. For a long run relationship to exist between retail, wholesale and farm prices there must be a cointegrating relationship. For this reason we test a further hypothesis for the long run case as given in (6) and (7) opposite:

$H_{0}^{L R}: \Pi=\alpha \beta^{\prime}=0$

and $H_{1}^{L R}: \Pi=\alpha \beta^{\prime} \neq 0$ 
Where $\alpha \beta$ is the matrix of unknown parameters representing the long run dynamics. In the case of any exogenous pricing by any of the three sectors one would expect to find the null hypothesis rejected. The next section reports the estimation of the VAR.

\section{Econometric Results - Vector Error Correction Model}

With the lag length established and the identification of cointegrating relations within the model, the VECM of lag length three was estimated. The results are given in table 2. In the short run, there is evidence that farm and wholesale prices are significantly related. This implies that as wholesale prices rise farm prices tend to rise after two lags in the wholesale price. Wholesale and retail prices are insignificantly related in the short run, suggesting that there is no link in their pricing strategies, although when switching the relationship around, retail prices are significantly related to wholesale prices with two lags. The long run dynamics are represented by the coefficients placed upon $B P(-3), W P(-3)$ and $F P(-3)$. Farm prices are significantly related to wholesale prices but not to retail prices. Retail and wholesale prices are also significantly related showing that for a rise in $W P$ there is a rise in $B P$.

Table 3 presents the estimated $\beta$ 's and $\alpha$ 's which are the long run parameters estimated by the Johansen and Juselius test. The estimation suggests that there are two cointegrating equations. The first is normalised to retail prices, $B P$, and the second is normalised to $W P$ and $B P$. The first relationship shows that both $B P$ and $F P$ are cointegrated at a high level of significance. $W P$, the wholesale price, is not cointegrated to either $B P$ or $F P$. This is an important result and may be due to anti-competitive pricing. The second cointegrating relationship indicates that $F P$ is not cointegrated with $B P$ and $W P$. Overall, the cointegration results show that all three prices are cointegrated.

The Johansen and Jeselius (1988) tests for cointegration applied to the retail, wholesale and farm prices provide an interesting outcome. The intuition behind the outcome indicates that the wholesale sector over the time period in question may have followed a pricing strategy not driven solely by market forces in the long run. In other words, there may have been inefficiency as a result of some anticompetitive behaviour. One reason for this may be the evidence and impact of increasing consolidation within the industry as put forward by Kaufman (2002) which suggested that wholesalers were becoming more powerful. In the short run and long run the VECM shows evidence of increasing wholesale prices tending to increase farm prices but in terms of the long run cointegration between wholesale, farm and retail prices, wholesale prices are exogenous to the system. Although a long run relationship does exist between all three price series, wholesale prices are not adjusting to movements away from the long run trend. Instead it appears that farm and retail prices are adjusting. It is 
possible to interpret this as a sign of anticompetitive behaviour on the part of the wholesale sector. Therefore it is possible that with exogenous wholesale prices, the bargaining power of farmers could have been restricted, through such concepts as countervailing power and vertical restraints as put forward by Xiu and Sexton (2003).

In the short and long run, as shown by the VECM, price transparency may be giving farmers increased bargaining power linked to increased knowledge of retail prices and an indication of demand through scanner prices, thus, facilitating improved contractual agreements on supply characteristics (such as animal specifications) and price. In this case there is no evidence suggesting that wholesalers are imposing market power on farmers shown by the short run dynamics indicating a positive relationship between prices.

\begin{tabular}{lccc}
\hline $\begin{array}{l}\text { Independent } \\
\text { Variables }\end{array}$ & $\mathbf{D}(\mathbf{B P})^{\mathbf{a}}$ & $\begin{array}{c}\text { Dependant Variables } \\
\mathbf{D}(\mathbf{W P})^{\mathbf{a}}\end{array}$ & $\mathbf{D}(\mathbf{F P})^{\mathbf{a}}$ \\
\hline $\mathbf{D}(\mathbf{B P}(-\mathbf{1}))$ & -0.707449 & -0.019200 & -0.039751 \\
& $(-5.53740)$ & $(-0.21479)$ & $(-0.64128)$ \\
$\mathbf{D}(\mathbf{B P}(-2)$ & -0.621931 & 0.113351 & 0.068666 \\
& $(-4.27467)$ & $(1.11354)$ & $(0.97273)$ \\
$\mathbf{D}(\mathbf{W P}(-1))$ & 0.046522 & 0.150759 & 0.244968 \\
& $(0.20208)$ & $(0.93598)$ & $(2.19313)^{* *}$ \\
$\mathbf{D}(\mathbf{W P}(-2))$ & -0.439298 & -0.152339 & 0.439620 \\
& $(-1.90255)^{* *}$ & $(-0.942299)$ & $(3.92415)^{* * * *}$ \\
$\mathbf{D}(\mathbf{F P}(-\mathbf{1}))$ & -0.057026 & 0.057573 & 0.038710 \\
& $(-0.17879)$ & $(0.25799)$ & $(0.25014)$ \\
$\mathbf{D}(\mathbf{F P}(-2))$ & 0.387865 & -0.028203 & -0.526025 \\
& $(1.29854)$ & $(-0.13496)$ & $(-3.62970)$ \\
$\mathbf{C}$ & 48.73931 & -1.852899 & 8.623412 \\
& $(1.42897)$ & $(-0.07765)$ & $(0.52109)$ \\
$\mathbf{B P}(-3)$ & -0.351138 & 0.121664 & 0.030931 \\
& $(-2.86813)$ & $(1.42039)$ & $(0.52071)$ \\
WP(-3) & 0.291415 & -0.105417 & 0.287167 \\
& $(1.38528)^{*}$ & $(-0.71623)$ & $(2.81352)^{* * * *}$ \\
$\mathbf{F P}(-3)$ & 0.018159 & -0.88450 & -0.426732 \\
& $(0.06892)$ & $(-0.47982)$ & $(-3.33816)$ \\
DUMBP & -0.022286 & 0.010278 & 0.007178 \\
& $(-1.54309)$ & $(1.01719)$ & $(1.02439)$ \\
\hline a t-statistics in parentheses & & \\
* Significant at a 10\% level, $* *$ Significant at a 5\% level and **** Significant at $0.5 \%$ level
\end{tabular}

Table 2 Short Run Vector Error Correction Estimates; Monthly Data Between January 1998 and February 2003.

\begin{tabular}{|c|c|c|}
\hline Equations $^{\text {b }}$ & $\beta$ 's & $\alpha$ 's $^{\mathrm{c}}$ \\
\hline \multicolumn{3}{|c|}{ One Cointegrating Equation } \\
\hline BP & 1.000000 & $-0.863163(-3.4666) * * * *$ \\
\hline WP & -1.193138 & $0.174954(1.0113)$ \\
\hline $\mathbf{F P}$ & 2.041427 & $-0.447661(-3.9487) * * * *$ \\
\hline $\mathbf{C}$ & -46.33574 & - \\
\hline \multicolumn{3}{|c|}{ Two Cointegrating Equations } \\
\hline $\mathbf{B P}_{1}$ & 1.000000 & $-2.145018(6.6017)^{* * * *}$ \\
\hline $\mathbf{W P}_{1}$ & 0.000000 & $0.441010(1.6012)^{*}$ \\
\hline $\mathbf{F P}_{1}$ & 0.016457 & $0.066730(0.4263)$ \\
\hline $\mathbf{C}_{1}$ & -32.06175 & - \\
\hline $\mathbf{B P}_{2}$ & 0.000000 & $0.012678(0.0404)$ \\
\hline $\mathbf{W P}_{2}$ & 1.000000 & $0.001660(0.0062)$ \\
\hline $\mathbf{F P}_{2}$ & 11.96340 & $0.942307(6.2313) * * * *$ \\
\hline $\mathrm{C}_{2}$ & -1.697179 & - \\
\hline
\end{tabular}

Table 3 Estimated Long Run Parameters; $\alpha$ 's and $\beta$ 's. 
Another result from the cointegration tests implied that retail prices were not cointegrated with wholesale prices in the long run. However, in the short run, the VECM shows that increasing wholesale prices reduce retail prices but in the long run this is reversed. This outcome in the short run is inconsistent with the suggestions of Kaufman (2002). Kaufman (2002) suggested that: "suppliers are entering into joint ventures or cooperatives in order to meet the marketing needs of consumers" (pg. 33). Nevertheless, it is possible that the introduction of price transparency has impacted upon the wholesale sector and not the retail sector. With information on retail pricing, and, the popularity of meat products in the eyes of consumers, being made widely available through price transparency, it is possible that wholesalers are providing specific products to the retail sector to meet demand, and, thus, bargaining for higher prices, or, imposing an element of market power upon them. Furthermore, the cointegration test between retail and farm prices indicated that farm prices are set with no relation to retail prices. Therefore, direct procurement by retailers does not appear to have impacted upon farm prices. This was backed up by the VECM results indicating an insignificant relationship between farm and retail in the short and long run.

The number of observations was a weakness to the modelling procedure. This had an impact on the number of lags that could be applied to the models. The result of twelve lags on data corresponding to sixty-two observations was not statistically significant, especially in the context of the VECM for cointegration to establish that the error correction framework could be applied. Therefore, the ability to model significant seasonality was not possible. Seasonality as a factor within the US beef industry is over a longer period of time compared to other animal production such as hog but, in the case of this study, a six month lag in the supply relationship was statistically significant for the data.

In summary, the econometric estimations go a long way in assessing the relationship between farm, wholesale and retail prices. The major finding refers to all three price regimes being cointegrated. Furthermore, wholesale prices being weakly exogenous is an interesting finding highlighting the possibility of some inefficient behaviour within the market that may have had anticompetitive implications for the farm and retail sectors.

\section{Conclusion}

This paper has attempted to investigate the short and long run relationships between farm, wholesale and retail beef prices within the US beef industry in light of recent information pooling imposed through The Livestock Mandatory Reporting Act. A Johansen and Juselius (1990) cointegration test was applied to monthly time series data between January 1998 and February 2003 to test for any deviation is sectoral price regimes. The econometric analysis revealed the following findings: 
- US beef retail, wholesale and farm prices are cointegrated and therefore there is evidence of a unique combination of the three time series that is stationary;

- Wholesale prices are weakly exogenous to the system and therefore are driven by a separate stochastic trend;

- As a result of wholesale prices being weakly exogenous, wholesale prices do not adjust to deviations from the long run equilibrium which suggests that the sector may be pricing inefficiently; and

- Farm and retail prices are required to adjust to restore the long run equilibrium of the system and are driven by the same common trend.

The first major finding of this analysis is with regard to all three prices being found to be cointgrated. From this we can conclude that there is a long run stationary relationship between the three price regimes. Furthermore, the Johansen and Jeselius test suggested that the wholesale price regime was weakly exogenous to the system in the long run. This too is a major finding as it implies that there may have been some inefficiency within the market activity during the time period in question. Weakly exogenous wholesale prices could be due to the wholesale sector pricing inefficiently and thus being anticompetitive. One possible explanation of this finding is the increased levels of vertical coordination between producers and wholesalers.

The implications of this finding point towards the need for further work into the market activity of the wholesale sector within the US beef industry using cointegration analysis. Future research should be aimed at improving the modelling technique using the ECM framework. As time passes more data is being published by the ERS, allowing for more specific data analyses to be undertaken improving the validity of econometric analysis. It should aim to involve a firm specific or State specific analysis of the introduction of the Act within the wholesale sector, to test for price delineation in or across particular geographical areas of the US for individual cuts of beef. The use of cointegration analysis that is not yet formally used in US antitrust and merger cases as a potent tool has many benefits for assisting policy debates in this area. Furthermore, the benefits of such a study spread to helping reduce the averaging problem of national data and instead any modelling would be State specific and highlight, if any, regional problems of price delineation that cannot be fully and effectively identified at the national level. 


\section{References}

Albæk, S., Møllgaard, P., \& Overgaard, P. B., (1997), Government-Assisted Oligopoly Coordination? A Concrete Case, Journal of Industrial Economics, Vol. 45, No. 4, pp. 429443.

Azzam, A. M. \& Salvador, S., (2004), Information pooling and collusion: an empirical analysis, Information Economics and Policy, Vol. 16, pp. 275-286.

Chang, H. S \& Griffith, G., (1998), Examining long run Relationships Between Australian Beef Prices, Australian Journal of Agricultural and Resource Economics, Vol. pp. 369-387.

Dickey, D. A. \& Fuller, W. A., (1979), Distribution of the Estimators for Autoregressive Time Series with a Unit Root, Journal of the American Statistical Association, Vol. 74, pp. 240-250.

Engle, R. F. \& Granger, C. W. J., (1987), Cointegration and Error Correction: Representation, Estimation, and Testing, Econometrica, Vol. 55, No. 1, pp.251-276

ERS, 1999, Mandatory Reporting Act. Available at:

http://www.ers.usda.gov/Data/Meatscanner/LivestockMandatoryReportingAct.pdf

Greene, W. H., (2003), Econometric Analysis (International Edition), Prentice Hall, Pearson Education (New Jersey), $5^{\text {th }}$ Edition.

Gujarati, D. N., (2003), Basic Econometrics (International Edition), McGraw Hill Higher Education (New York), $4^{\text {th }}$ Edition.

Haley, M.,(2001), Agricultural Outlook, Economic Research Service, USDA, September.

Harris J. M., (2002), U.S. Food Marketing System 2002, Economic Research Service, USDA.

Johansen, S. \& Juselius, K., (1990), Statistical Analysis of Cointegration Vectors, Journal of Economic Dynamics and Control, Vol. 12, pp. 213-254.

Johansen, S., (1988), Maximum Likelihood Estimation and Inference on Cointegration - with Applications to the demand for money, Oxford Bulletin of Economics and Statistics, Vol. 52, pp. 160-210.

Kaufman, P. R., (2002), U.S. Food Marketing System 2002, Economic Research Service, USDA.

MacDonald, S. M., Ollinger, M. E., Nelson, K. E., \& Handy, C. R., (1999), Consolidation in US Meatpacking, Economic Research Service, USDA, Agricultural Economics Report, No. 785.

Mathews, K. H., Hahn, W. F. Jr., Nelson, K. E., Duewer, L. A., \& Gustafson, R. A., (1999), U.S. Beef Industry: Cattle Cycles, Price Spreads, and Packer Concentration, Economic Research Service, USDA, Technical Bulletin No. (TB1874).

Sexton, R. J., (2000), Industrialisation and Consolidation in the US Food Sector: Implications for Competition and Welfare, American Journal of Agricultural Economics, Vol. 82, No. 5, pp. 1087-1104. 
Von Ungern-Sternberg, T., (1996), Countervailing Power Revisited, International Journal of Industrial Organisation, Vol. 14, pp. 507-520.

Xia, T. \& Sexton, R. J., (2003), The Competitive Implications of Top-of-the-Market and Related Contract -Pricing Clauses, Working Paper, Department of Agricultural and Resource Economics, University of California, Davis, January 2003. 


\section{Appendices}

\section{Appendix A}

\section{A1. Jarque Bera Test for Normality}

\begin{tabular}{lcccc}
\hline & St. Deviation & Skewness & Kurtosis & JB \\
\hline Volume & 20.997 & -0.033 & 2.712 & 0.225 \\
& & & & $(0.893)$ \\
Retail Price & 20.997 & 0.389 & 1.944 & 4.440 \\
Wholesale Price & 15.972 & -0.140 & 2.103 & $(0.108)$ \\
& & & & 2.278 \\
Farm Price & 11.913 & 0.332 & 2.253 & $(0.320)$ \\
& & & & 2.582 \\
& & & & \\
\hline
\end{tabular}

Table A1 Skewness and Kurtosis Coefficients for all Variables

\section{Appendix B}

\section{B1. Augmented Dickey-Fuller Tests for Unit Roots}

ADF tests for unit roots were carried out on all three variables. The results are as follows:

\begin{tabular}{lrc}
\hline Variable & $\mathbf{I}(\mathbf{0})$ & $\mathbf{I}(\mathbf{1})$ \\
\hline BP & -0.964 & $-5.139 * *$ \\
WP & -2.218 & $-4.380^{* *}$ \\
FP & -1.877 & $-4.464 * *$ \\
\hline Significance at the 5\% level & \\
** Significance at the 1\% level &
\end{tabular}

Table B1 Augmented Dickey-Fuller Tests for Unit Roots

The ADF tests for unit roots show that $B P, W P$, and $F P$ are non-stationary in the levels and are stationary at first difference with a high level of significance. This result ensures the appropriate set up of the ECM framework and ensures that the summations of first differences measuring the short run dynamics are stationary.

\section{B2. Determination of Lag Length}

The following table presents the process by which the lag length of three $(p=3)$ was justified. The decision was made using the LR test supported by the AIC result.

\begin{tabular}{ccc}
\hline Number of Lags & Log Likelihood Result & AIC Result \\
\hline $\mathbf{1 2}$ & -446.987 & 23.264 \\
$\mathbf{1 0}$ & -472.821 & 22.659 \\
$\mathbf{8}$ & -498.050 & 22.077 \\
$\mathbf{6}$ & -515.717 & 21.262 \\
$\mathbf{4}$ & -532.135 & 21.262 \\
$\mathbf{3}$ & -528.439 & 19.799 \\
$\mathbf{2}$ & -551.073 & 19.799 \\
\hline
\end{tabular}

Table B2 Log Likelihood and Akaike AIC Results to Determine Significant Lag Length of ECM 


\section{B3. Johansen \& Juselius Test for Cointegration}

The following table presents the cointegrating vectors encountered by the cointegration test:

\begin{tabular}{|c|c|c|}
\hline Cointegrating Vectors & $\lambda_{M A X}$ & $\lambda_{\text {TRACE }}$ \\
\hline 1 Cointegrating Vector $\quad r=0$ & $44.564 * *$ & $106.050 * *$ \\
\hline 2 Cointegrating Vectors $r=1$ & $41.598 * *$ & $61.485^{* *}$ \\
\hline 3 Cointegrating Vectors $r=2$ & $19.887 * *$ & $19.887 * *$ \\
\hline
\end{tabular}

\section{Table B3 Multivariate Cointegration Test}

The multivariate cointegration test has provided two cointegrating vectors, therefore the rank is two for this model ${ }^{9}$. The cointegration results imply that the ECM will contain cointegrating relations and therefore stationary, long run solutions are guaranteed from the model outcomes.

\footnotetext{
${ }^{9}$ Both tests applied a hypothesis setting $\mathrm{H}_{0}: r=0$ and $\mathrm{H}_{1}: r \geq 0$.
} 